DOI:

10.1038/nrgXXXX
MILESTONE 13

\section{Size matters}

The year 1987 marked a quantum leap for DNA cloning with a tenfold increase in vector capacity. A vector carrying a $50-\mathrm{kb}$ insert, the largest available at the time, was useful for examining a single gene but far too small to also contain all regulatory regions. There was also growing interest in constructing comprehensive libraries covering the whole genomes of higher organisms - a supremely daunting task if undertaken in $50 \mathrm{~kb}$ fragments.

To increase capacity, Maynard Olson and colleagues at Washington University exchanged the classical cloning vehicle, a circular Escherichia coli plasmid, for what they called a yeast artificial chromosome (YAC): a linear DNA molecule that mimics a yeast chromosome, complete with centromere and telomeres. All necessary YAC elements were incorporated into circular plasmids that could be linearized in vitro during insertion of the exogenous DNA. The resulting linear fragment, carrying as much as several hundred $\mathrm{kb}$ of foreign DNA, faithfully replicated in yeast.

YACs were eagerly adopted by the scientific community, particularly to establish physical maps of whole genomes. Yet, with their increased use, some problems surfaced: many clones turned out to be chimaeras of noncontiguous DNA fragments, inserts were occasionally unstable and purification of YACs proved challenging due to contamination from endogenous yeast chromosomes. People started to miss the simplicity of a bacterial cloning system.

In 1992, the time was ripe to revisit $E$. coli with the aim of adapting it for large-fragment cloning. A group at the California Institute of

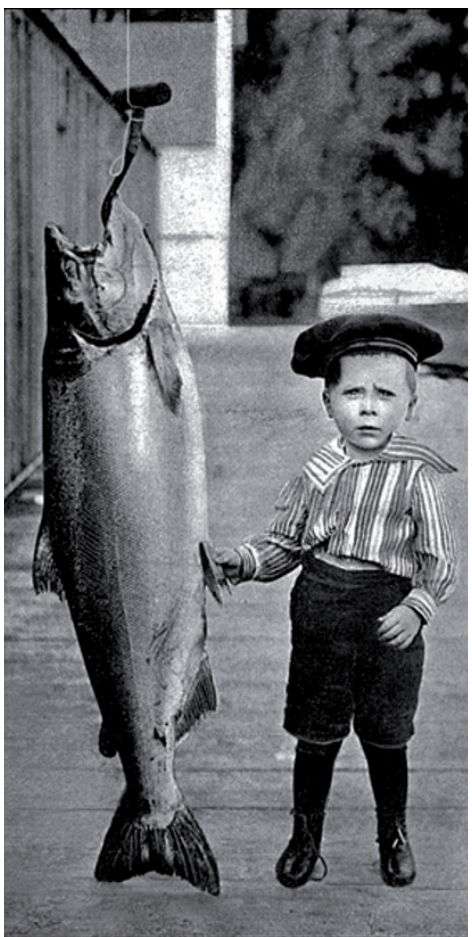

Technology led by Melvin Simon modified an endogenous circular plasmid in E. coli, the fertility (F) factor present at one or two copies per cell, to create a cloning vector. In reference to its yeast cousin, they called it bacterial artificial chromosome (BAC). With a cloning capacity of $\sim 300 \mathrm{~kb}$, BACs are not as potent as YACs, but they have all the advantages of a bacterial vector: stability, and ease of manipulation and purification.

Today YACs are still in use; however, BACs have become the workhorses in genomic research for any application that requires large DNA inserts.

Nicole Rusk, Associate Editor, Nature Methods

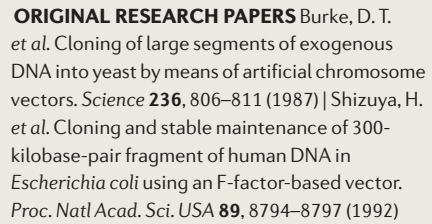

